\title{
Regime de metas de inflação em países da américa latina: uma revisão teórica
}

\author{
Kim Ellwanger \\ Universidade do Vale dos Sinos \\ Brasil
}

Data da Submissão: 18/03/2018

Data de aceite: 20/02/2019

\begin{abstract}
RESUMO
O regime de metas de inflação é uma estratégia de política monetária que tem por objetivo a estabilidade de preços da economia. Esse artigo tem por objetivo analisar a condução do regime de metas de inflação nos países selecionados da América Latina, a exemplo do Brasil, Chile, Colômbia, México e Peru, descrevendo também suas respectivas autoridades monetárias. Descreveu-se as características e objetivos deste regime de política monetária, e também dos demais regimes monetários utilizados pelos países do globo. Analisou-se a condução do regime no período entre 2002 a 2014, e se constatou que apesar das dificuldades em determinados países em cumprir com a meta em alguns períodos específicos, o regime de metas inflacionárias, de um modo geral, tem obtido um resultado no mínimo satisfatório no controle da inflação nos países estudados. Sendo assim, considerado um importante regime monetário na economia atual.
\end{abstract}

Palavras-chave: Regime de metas de inflação, Política monetária, América Latina.

\section{INTRODUÇÃO}

Na década de 90, alguns países adotaram o regime de metas de inflação. Esse sistema é caracterizado como um ambiente de política monetária no qual é anunciado oficialmente as metas quantitativas para a taxa de inflação a serem atingidas, isso demonstra de forma explícita, que o principal objetivo das autoridades monetárias é a estabilidade de preços.

Ao longo dos vinte e cinco anos desde que o primeiro país, a Nova Zelândia, adotou o regime de metas de inflação, esse arranjo ganhou adeptos e se consolidou com um dos principais regimes monetários utilizados na atualidade. Entretanto não há um consenso tanto no campo acadêmico quanto aos policy markers a respeito da sua real eficácia na condução da política monetária, conforme abordado por Ayres et al. (2014), Ball (2011), Ball e Sheridan (2005), Bonga-Bonga e Kabundi (2015), Brito e Bystedt (2010), Hebbel-Schmidt (2009), Neves e Oreiro (2008), Pooter et al. (2014), Rodrigues (2003). Na América Latina, esse 
regime foi implementado no último trimestre de 1990 no Chile, em 1999 no Brasil e na Colômbia, em 2001 no México, em 2002 no Peru e em 2011 no Paraguai. ${ }^{1}$

O regime de metas de inflação tem como pressuposto uma meta explícita para a taxa de inflação, e uma responsabilidade formal por parte da autoridade monetária para o cumprimento da meta estabelecida. Mishkin (1999) argumenta que, nesse regime, as autoridades monetárias têm a oportunidade de utilizar todas as informações disponíveis para conduzir a melhor estratégia para a política monetária. Tal fato não é possível em outros regimes monetários de âncora nominal, em que há apenas uma variável passível de ser controlada. De acordo com Biondi (2006), o principal instrumento da política monetária passa a ser a taxa de juros que, conforme a regra de Taylor, ela deve ser elevada quando há inflação e reduzida quando os preços estão em queda. Há um consenso na literatura que a adoção do regime de metas inflacionárias de fato atinge este objetivo, entretanto não há também concordância sobre os benefícios gerados no lado real da economia, em especial sobre o crescimento do produto, o qual diverge conforme a metodologia, o período e os países analisados. Nesse sentido, Brito e Bystedt (2010) não encontraram evidências empíricas que comprovem que a adoção do regime de metas de inflação resultou em um melhor desempenho em relação ao crescimento do produto. Entretanto, em trabalho anterior, Brito e Bystedt (2006) concluíram que em países da América Latina o regime de metas de inflação é um regime monetário de sucesso, pois reduziu a taxa de inflação bem como a sua volatilidade e não reduziu o crescimento econômico, inclusive encontraram evidências para um possível aumento na taxa de crescimento do produto.

Do ponto de vista teórico, a adoção do regime de metas de inflação ocorre sob um mesmo prisma, porém o desenho institucional varia para cada país, influenciado pelas condições econômicas iniciais, fatores culturais, características operacionais, dentre outros fatores, conforme abordado por Neves e Oreiro (2008). Ayres et al. (2014) sugerem em suas análises que o regime de metas de inflação apresenta diferentes resultados em relação à inflação e ao crescimento do produto dependendo da região analisada. Os autores sugerem ainda que pesquisas futuras analisem o porquê da existência de diferenças regionais e os diferentes impactos que o regime de metas de inflação gera em cada região do mundo.

Ball e Sheridan (2005), por sua vez, não encontraram evidências significativas que comprovem que o regime de metas de inflação de fato teve êxito. Os resultados encontrados pelos autores, em geral, sugerem que ao adotar este regime monetário não foi percebido uma

\footnotetext{
${ }^{1}$ Para um maior detalhamento, veja-se em Morandé (2002) e as informações disponibilizadas pelos respectivos bancos centrais de cada país.
} 
melhora quanto ao controle da inflação, crescimento do produto e taxa de juros quando comparado a outros regimes monetários.

Abo-Zaid e Tuzemen (2012) analisaram países desenvolvidos e em desenvolvimento a respeito dos possíveis benefícios gerados pela implantação do regime de metas inflacionárias, e os resultados apontam que os países em desenvolvimento que adotaram este regime monetário apresentaram uma inflação mais estável e um crescimento do produto maior, e também mais estável. Os autores encontraram resultados semelhantes para os países desenvolvidos e com destaque a uma maior eficácia em relação à política físcal. Pooter et al. (2014) pesquisaram se as expectativas inflacionárias melhoraram com a implementação de metas inflacionárias no Brasil, Chile e México, concluíram que estas melhoraram consideravelmente entre o período de 2002 a 2013. Já Silva (2007) argumenta que os aspectos relacionais a taxa de câmbio sobre a inflação, os desequilíbrios fiscais, financeiros e externos, e ainda a vulnerabilidade e a instabilidade econômica tendem a atrapalhar o funcionamento do regime de metas de inflação, e em seu estudo conclui que nos países emergentes analisados, a implementação deste regime monetária não melhorou nem piorou o seu desempenho econômico.

O regime de metas de inflação é frequentemente alvo de discussão no campo político, teórico e social, isto ocorre não só devido a meta de inflação encontra se dentro ou fora do esperado, mas as externalidades que podem resultar na economia. Como a taxa de juros passa a ser o principal mecanismo de política monetária, discute-se o impacto negativo que, uma taxa de juros muito elevada, pode ocasionar as economias, principalmente, nas variáveis como o produto e emprego.

Neves e Oreiro (2008) argumentam que não há um único modelo do regime de metas de inflação a ser implementado, e que a busca por conjuntos estruturais que resultam em maior eficiência é benéfica, a exemplo da Nova Zelândia que desde a adotam do regime de metas de inflação já utilizou diferentes índices de inflação buscando melhorar a condução da política monetária. Cecchetti e Ehrmann (1999) pesquisaram se a implementação do regime de metas de inflação gera a existência de um trade-off entre a inflação e o produto da economia, os resultados encontrados apontam para uma menor volatilidade da inflação e do produto em oito dos nove países analisados. Em trabalho realizado por Mendonça² (2001; citado por Rodrigues, 2003) que analisou a existência de um trade-off entre inflação e desemprego, os resultados encontrados nos oito países analisados sugerem que a queda da

\footnotetext{
${ }^{2}$ Metas de inflação: uma análise preliminar para o caso brasileiro
} 
inflação ocasionou um aumentou na taxa de desemprego, existindo assim uma taxa de sacrifício.

Mollick, Cabral e Carneiro (2008) analisaram os impactos que o regime de metas de inflação em países desenvolvidos e em desenvolvimento ocasionou sobre o crescimento do produto. Os resultados encontrados pelos autores afirmam que ocorreu um crescimento da renda per capita nos países que adotaram este regime, contudo em menor proporção nos países em desenvolvimento.

Neste contexto o objetivo do presente artigo é analisar a condução do regime de metas de inflação nos países selecionados da América Latina, descrevendo suas respectivas autoridades monetárias. Definiu-se como recorte geográfico a América Latina, delimitando alguns países específicos, os quais são, Brasil, Chile, Colômbia, México e Peru. A relevância do estudo justifica-se pelo fato de se analisar o regime monetário adotado por alguns dos principais países da América Latina.

O estudo está subdividido em seis seções, além dessa introdução. A segunda seção traz a concepção do sistema de metas de inflação. A terceira seção aborda os regimes monetários utilizados pelas diferentes autoridades monetários do globo. A quarta apresenta a estrutura dos bancos centrais e os principais aspectos monetários dos países selecionados. A quinta seção apresenta uma revisão de estudos empíricos que tiveram como foco o regime de metas de inflação. Por fim, na sexta, encontram-se as considerações finais.

\section{CONCEPÇÃO DE METAS INFLACIONÁRIAS}

O regime de meta de inflação foi adotado inicialmente pela Nova Zelândia, em março de 1990. Esse regime monetário ganhou adeptos com o passar do tempo, e atualmente é adotado por 34 países $^{3}$ de acordo com o relatório do FMI (2014). Os países com histórico de elevadas taxas de inflação obtiveram uma maior estabilidade de preços após adoção do sistema de meta de inflação. Essa é uma das principais razões porque, com o passar dos anos, mais países estão adotando deste sistema. Na maior parte dos países que adotam o regime de metas de inflação a meta é definida em conjunto pelo Banco Central e o governo.

As decisões de política monetária são tomadas de maneira mais clara e transparente, proporcionando ao público uma fiscalização do grau de comprometimento da autoridade

\footnotetext{
3 Armênia, Republica Dominicana, Guatemala, República Checa, Albânia, Brasil, Colômbia, Geórgia, Gana, Hungria, Islândia, Indonésia, Israel, Coreia do Sul, Moldávia, Nova Zelândia, Paraguai, Peru, Filipinas, Romênia, Servia, África do Sul, Tailândia, Turquia, Uganda, Austrália, Canadá, Chile, Japão, México, Noruega, Polônia, Suécia e Reino Unido.
} 
monetária no cumprimento das metas. Além disso, há um entendimento por parte dos agentes econômicos sobre os limites e alcances da política monetária, bem como dos custos e benefícios resultante das decisões tomadas como aborda Silva (2001).

Para atingir a estabilidade dos preços, a política monetária necessita, segundo Hammond (2012), de uma âncora nominal. Isso significa que é preciso fixar uma variável nominal com o objetivo de obter uma inflação baixa e estável ao longo do tempo. O estabelecimento de âncora nominal torna-se necessária para manter a estabilidade dos preços porque proporciona condições que fazem o nível de preços ser único, auxiliando a reduzir as expectativas de inflação como aborda Mishkin (1999). Também pode ser compreendida de uma maneira mais ampla na qual limita os formuladores da política monetária em tomar ações tendo em vista o curto prazo e prejudicando o longo prazo. Em outras palavras, uma expansão monetária tem o efeito de aumentar o produto e a diminuir o desemprego no curto prazo. Entretanto, no longo prazo, os agentes irão ajustar os preços e salários resultando em um aumento na taxa de inflação.

$\mathrm{Na}$ visão de Mishkin (2000) existem cinco elementos básicos para a estratégia do regime de meta de inflação, que são: i) anúncio público das metas numéricas para a taxa de inflação para um ou mais horizontes de tempo; ii) compromisso claro com a estabilidade de preços como principal objetivo da política monetária; iii) o uso de uma estratégia de informação em que algumas variáveis sejam utilizadas como parâmetros às decisões no que se referem aos instrumentos da política; iv) o aumento da transparência das estratégias de política monetária, por meio da comunicação ao público e aos mercados sobre os planos, objetivos e decisões da autoridade monetária; e v) o aumento da responsabilidade do Banco Central em atingir as metas inflacionárias. A estrutura do regime de meta de inflação, para King (2005), combina dois elementos distintos: a) uma meta numérica para a inflação num médio prazo; b) uma resposta para os choques econômicos no curto prazo.

A meta de inflação, de acordo com o FMI (2005), está associada a menores taxa de inflação, menores expectativas e a uma menor volatilidade da inflação quando comparado a países que não adotaram este regime. A independência do Banco Central distingue-se de duas maneiras: i) independência de definir a meta, nesse caso, o Banco Central tem a autonomia de decidir qual será a meta a ser buscada; e ii) independência instrumental, na qual o Banco Central tem a liberdade de conduzir a política monetária para atingir a meta sem interferência política em suas decisões.

Um crescimento econômico com estabilidade de preços é o objetivo de uma política monetária comprometida com o país. E o sistema de meta de inflação permite que o Banco 
Central tenha autonomia para executar seu papel, sem sofrer pressões políticas para desviar do mesmo dado o trade-off existente entre inflação e desemprego. Além disto, este regime proporciona um crescimento da economia mais estável, e com capacidade de responder aos choques econômicos sem perder a credibilidade.

O regime de metas de inflação é uma das estruturas de política monetária para se atingir a estabilidade dos preços, neste regime o controle da inflação é a prioridade da autoridade monetária possuindo essas regras claras quanto as ações a serem desempenhadas para o atingimento da meta, resultando em uma maior transparência as ações do governo, o que permite a criação de um ambiente onde as expectativas dos agentes econômicos se dão de forma mais racional. Anderson et al. (2013), analisa a eficiência do regime de metas de inflação no período de 2007 a 2012, comparando países membro do OCDE (Organização para a Cooperação e Desenvolvimento Econômico) que adotaram o regime de metas de inflação com países que não o adotaram. Os autores concluíram que os países que adotaram o regime de metas de inflação obtiveram, na média, um melhor desempenho no crescimento do produto no período analisado.

A gestão do regime de metas de inflação, conforme Arestis (2003), pode ser compreendida e dividida em três etapas: i) delegação do controle da inflação às autoridades monetárias, que são responsáveis por estimar um modelo de previsão para a inflação por meio das variáveis relevantes; ii) anunciar publicamente a meta de inflação, sendo responsabilidade das autoridades monetárias atingir a meta estabelecida; iii) utilizar os instrumentos de política monetária, como a taxa de juros, visando reduzir as pressões inflacionárias e manter a inflação dentro da meta.

De acordo com Cabral (2013) existem diversos modelos que tem por finalidade representar o regime de metas de inflação, e a maioria dos modelos se baseia em três equações:

(i) A Curva de Phillips, que determina a inflação corrente via desemprego, e que podem também incluir como determinantes a inflação passada ou a projeção da inflação futura. A expressão para a Curva de Phillips, segundo Biondi (2006), pode ser definida conforme abaixo:

$$
\pi=\pi^{e}-\beta\left(\mu-u^{n}\right)+\varepsilon
$$


Onde: $\pi$ é a inflação corrente; $\pi^{e}$ é a inflação esperada; $\beta$ é o parâmetro que indica a inclinação da curva de Phillips, $\mu$ é a taxa de desemprego; $u^{n}$ é a taxa natural de desemprego; $\varepsilon$ representa o choque de oferta.

(ii) A Curva IS, que relaciona negativamente os juros e o hiato do produto 4 . Conforme Barbosa (2004), a curva IS pode ser expressa conforme abaixo:

$y-y^{*}=-\partial\left(p-p^{*}\right)$

Onde: $y$ é o produto real; $y^{*}$ é o produto potencial; $\partial$ é um parâmetro maior que zero; $p$ é a taxa de juros de curto prazo; $p^{*}$ é a taxa de juros de longo prazo.

(iii) A função de reação da autoridade monetária, conhecida também como Regra de Taylor, que determina o nível da taxa de juros nominal com base no desvio da inflação da meta estabelecida. Quando a inflação estiver acima da meta, a taxa de juros deve ser aumentada, e quando a inflação estiver abaixo da meta estabelecida a taxa de juros deveria ser reduzida. Para Biondi (2006), a Regra de Taylor pode ser expressa da seguinte forma:

$i=i^{*}+\alpha\left(\pi-\pi^{*}\right)$

Em que: $i$ é a taxa de juros; $i^{*}$ é a taxa de juros compatível com a taxa de desemprego natural; $\alpha$ é um parâmetro que representa o impacto de desvios da inflação na taxa de juros; $\pi$ é a inflação corrente; $\pi^{*}$ é a meta de inflação.

Os modelos que representa o regime de metas de inflação possuem suas próprias curvas com suas particularidades, contudo é comum na maior parte dos modelos é o mecanismo de transmissão no qual a manipulação dos juros controla a inflação. Cabral (2013) representa esse mecanismo do canal de transmissão conforme o diagrama abaixo:

$$
i_{t} \stackrel{\text { Curva IS }}{\longrightarrow} y_{t+1} \stackrel{\text { Curva de Phillips }}{\longrightarrow} \pi_{t+2}
$$

\footnotetext{
${ }^{4}$ Hiato do produto é a diferença entre o produto corrente e o produto potencial.
} 
Sendo assim, o banco central determina a taxa de juros, que através da curva IS, determina o produto após um intervalo de tempo. O produto determina a inflação no segundo intervalo de tempo, logo para controlar a inflação este regime monetário controla a demanda agregada.

\section{REGIMES MONETÁRIOS}

Para Mishkin (1999), há três regimes básicos de política monetária com uma âncora nominal explícita. O primeiro deles são as metas monetárias que se constitui pelo anúncio de metas para determinado agregado monetário, servindo de referência para as expectativas de inflação, sendo assim uma estrutura indireta para atingir a meta inflacionária. Esse regime permite que o banco central se preocupe com o ambiente interno da economia, possibilitando lidar com as flutuações temporárias do desempenho econômico e interferir em choques que possam ocorrem, não ocorrendo tanta influência do ambiente externo como o sistema de metas cambiais. De acordo com Hammond (2012), este regime falhou em diversos países porque a demanda por moeda não é uma função estável, esta instabilidade, na maior parte dos casos, é resultado da desregulamentação, inovação financeira e novos tipos de meio de pagamento. Segundo Batini (2005), a meta monetária envolve em definir uma meta anual para o crescimento do agregado monetário, assumindo que ao controlar o crescimento do agregado monetário estará controlando a inflação, este regime define uma regra fixa para o crescimento do estoque de moeda e surgiu pela escola monetarista liberado por Milton Friedman. Para Leal e Feijó (2011), devido às crises ocorridas entre os anos 1970 a 1980 esse regime monetário era praticamente um consenso na economia internacional, no qual o crescimento de moeda era calculado somando a taxa de crescimento do produto com a inflação pretendida.

O segundo regime é o de metas cambiais, também que pode ser designado de indireto quanto ao controle da inflação. Esse arranjo monetário se caracteriza por atrelar o valor da moeda nacional a uma moeda internacional de um grande país e com baixo histórico de inflação, em geral adota-se o dólar americano. Ao fixar o valor da moeda doméstica, o país almeja taxas de inflação similares ao país âncora, a qual está fixada ou sofre variações limitadas por um sistema de bandas. Para Mishkin (1999), as principais vantagens em utilizar esse sistema são: a) a âncora nominal fixa a inflação dos preços dos bens comercializados internacionalmente, contribuindo para manter a inflação sob controle; b) se a moeda escolhida tem credibilidade, as expectativas para a inflação tendem a estar correlacionadas com o país da moeda âncora; c) automaticamente conduz a política monetária; d) fácil de ser 
compreendida pelo público porque é clara e transparente. Com o câmbio fixo, a política monetária é endógena, ou seja, a taxa de juros do país tem uma relação direta de equilíbrio com a taxa de juros do país âncora. Isso significa que caso ocorra uma elevação da taxa de juros no país âncora deverá haver uma elevação no país que está utilizando o regime de metas cambiais. Essa característica seria a principal desvantagem deste regime já que o país perde a autonomia em administrar a política monetária de forma independente, pois não possui a flexibilidade de adequar a taxa de juros para a real situação interna do país, ficando refém a moeda âncora. Outra desvantagem é que o país torna-se mais suscetível a ataques especulativos contra a sua moeda, como ocorreu na Inglaterra e na Alemanha em 1992, no México e na Argentina em 1994, e na Rússia e no Brasil em 1998, por essa razão é fundamental que o Banco Central possua reservas significativas. Batini (2005) argumenta que, nesse aspecto, é uma estrutura de política monetária arriscada principalmente para os países com um fluxo significativo de capitais internacionais.

Nesse regime, argumentam Leal e Feijó (2011), a taxa de câmbio fixa é de responsabilidade da autoridade monetária, e não do mercado. Sendo assim, Carvalho et al. (p.342, 2007), explicam que "[...] o Banco Central precisa dispor de reservas internacionais para intervir no mercado de câmbio e com isso garantir a manutenção da paridade fixa.". Além de dispor de reservas para manter a paridade de câmbio fixa, o banco central deve manter a taxa de juros atrativa para que se evite a fuga de capitais estrangeiros aplicados no país e que não ocorram ataques especulativos contra a moeda nacional. Nos anos 90, conforme Biondi (2006), alguns países da América Latina e da Ásia Oriental adotaram o regime de metas cambiais com a pretensão de estabilização economia, contudo os resultados foram pouco satisfatórios, as crises financeiras ocorridos no período obrigaram os países a buscarem outras alternativas de âncora nominal, e a estratégia de política monetária baseada em metas inflacionária tornou-se uma das opções para estes países.

O terceiro regime é o de metas de inflação, que utiliza como âncora nominal a própria inflação, sendo que essa depende do índice de inflação a ser utilizado como base. A escolha do índice de preço que a autoridade monetária utilizará como referência tem no atingimento das metas, de acordo com a maioria dos teóricos, o mais coerente é adotar o núcleo da inflação que desconsidera choques temporários que possam ter ocorrido e reflete a tendência da inflação, com isso o índice de preço tende a ser menos volátil. Leal e Feijó (2011) argumentam que o alicerce teórico base das ideias desse regime monetário é a síntese neoclássica, que incorporou a curva de Phillips, a corrente monetarista (que defende uma taxa 
natural de desemprego e que as políticas monetárias afetam as variáveis reais da economia) e as expectativas racionais.

O quarto regime monetário, utilizado por diversos países, é quando se utiliza uma âncora nominal implícita, não existe uma meta oficial para o agregado monetário, cambial ou inflação. Esse regime adota estratégias híbridas, é menos transparente ao público, o que pode ocasionar maior volatilidade no mercado financeiro e incerteza a respeito do curso da inflação (MISHKIN, 1999). Devido à falta de comunicação aos agentes de uma meta explícita, esse regime permite alto grau de discricionariedade, as autoridades monetárias tem a capacidade de impor as medidas que julgam necessárias frente as suas análises. Conforme Leal e Feijó (2011), o principal argumento ao justificar esse regime monetário é o sucesso que os Estados Unidos, um dos países que adotam esta política macroeconômica, vem alcançando na manutenção da estabilidade monetária. Em relação as desvantagens, explicam os autores, é a falta de transparência existente na condução desse regime monetário.

\section{ESTRUTURA DAS AUTORIDADES MONETÁRIAS}

Conforme estudo de Fraga et al. (2003) os países emergentes enfrentam desafios na condução do regime de metas inflacionarias maiores do que os países desenvolvidos. Os argumentos para este fato, conforme abordam os autores, são a menor credibilidade frente a autoridade monetária, um ambiente econômico tradicionalmente mais instável, um histórico de inflação mais elevada, e instituições fracas.

A América Latina era uma região caracterizada por elevadas taxas de inflação, no início da década de 1990 possuía as maiores taxas de inflação mundial. Em decorrência deste grave problema econômico e das crises enfrentadas pelos países na década de 1990, diversos países abandonaram seus regimes monetários e adotaram o regime de metas de inflação. De acordo com Zettel (2006) os países da América Latina enfrentam quatro grandes desafios, que são: i) reduzir os níveis de inflação, que em geral continuam elevados; ii) fortalecer as instituições; iii) reduzir o risco de dominância fiscal e externa; e iv) construir credibilidade frente ao público em geral.

O Chile adotou o regime de metas de inflação em 1990, foi o pioneiro na adoção deste regime monetário na América Latina. A primeira etapa que durou até 1999, o câmbio chileno era controlado por bandas cambiais, durante este período a economia estava em elevado grau de crescimento, o governo apresentava superávits fiscais, taxas de desemprego baixa, e grande entrada de fluxos de capitais internacionais (movimento que também ocorreu em diversos 
países da América Latina durante a década de 1990), contudo a credibilidade do banco central frente aos agentes econômicos precisa ser construída, o horizonte da meta de inflação era de curto prazo. A segunda etapa, segundo Nunes (2014), ocorre após 1999 como resultado das crises econômicas do período, o governo decidiu abandonar o regime de bandas cambiais, e adotou o regime de câmbio flutuante, intervindo pelo banco central quando julga que a moeda está em uma trajetória longe do seu preço de equilíbrio, esta etapa o regime se tornou mais flexível. Para que um banco central possa cumprir seu objetivo de forma mais eficiente é necessário que se proteja esta autoridade frente a pressões associadas a ciclos políticos, com este objetivo argumentam Corbo e Hernández (2005) e Mishkin (2004), em 1989 conferiu-se esta autonomia e independência a autoridade monetária chilena.

A política monetária é conduzida de maneira transparente ao público, com relatórios publicados periodicamente pelo banco central a respeito dos principais assuntos econômicos bem como suas projeções para a economia chilena (BBC, 2016). Deste a adoção do regime de metas inflacionárias o Chile reduziu de forma contínua a taxa de inflação, como observam Corbo e Hernández (2005), durante o período de 1991 a 1995 a taxa de inflação média foi de 12,1\%, no período de 1996 a 2000 a taxa de inflação média foi de $4,8 \%$ e no período que corresponde a 2001 a 2004 a taxa média reduziu-se para 2,2\%. Segundo Mishkin (2004), o Chile tem obtido grande sucesso na redução da inflação, com níveis similares aos encontrados em economias desenvolvidas, e ao mesmo tempo com um elevado crescimento econômico.

Gráfico 1: Taxas de inflação registradas no Chile

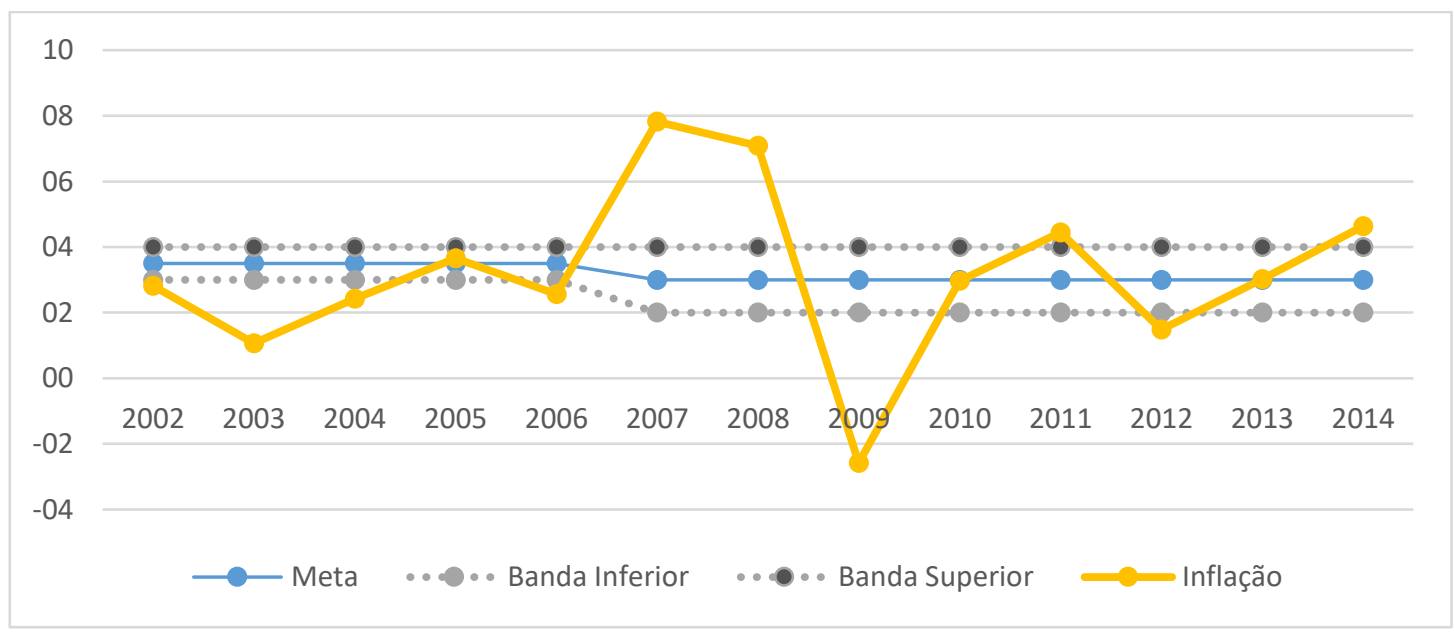

Fonte: Banco Central do Chile. Elaboração do autor.

Conforme pode ser observado no gráfico acima, a inflação chilena tem se mantido relativamente estável, com exceção ao período da crise internacional financeira que se iniciou 
um 2007, onde por dois anos seguidos a inflação supera a banda superior estabelecida e em 2009 ocorre uma deflação.

O Banco Central do México foi fundado em 1 de setembro de 1925, o primeiro objetivo do banco foi de promover o crédito ao país. Durante a década de 90 o México experimentou diversas políticas monetárias e cambiais, as quais pode-se separar em três grandes grupos, o primeiro uma meta cambial de bandas que resistiu até a crise financeira de 1994, o segundo quando se aplicou um regime metas para o agregado monetário e a livre flutuação do câmbio, e o terceiro quando a partir de 1999 o México iniciou a fase de transição para o regime de metas de inflação (GALINDO e ROS, 2006).

A modernização do Banco Central do México se iniciou em 1994 com a independência do governo, um ano após o México enfrentar uma grave crise financeira (BM, 2016). Em 2001, o país adotou oficialmente o regime monetário de metas de inflação, o qual vinha sendo implementando gradualmente desde 1999. O banco é dirigido por cinco membros, designados pelo presidente da república e com aprovação do senado. O regime cambial adotado desde o final de 1994 é flutuante, onde o mercado é quem precifica a moeda mexicana (BM, 2016). Conforme Nunes (2014), após a adoção este regime monetário a política monetária mexicana se tornou mais eficaz e com maior grau de transparência, as publicações periódicas do banco central sinalizam de forma mais efetiva as intenções da autoridade monetária.

Gráfico 2: Taxas de inflação registradas no México

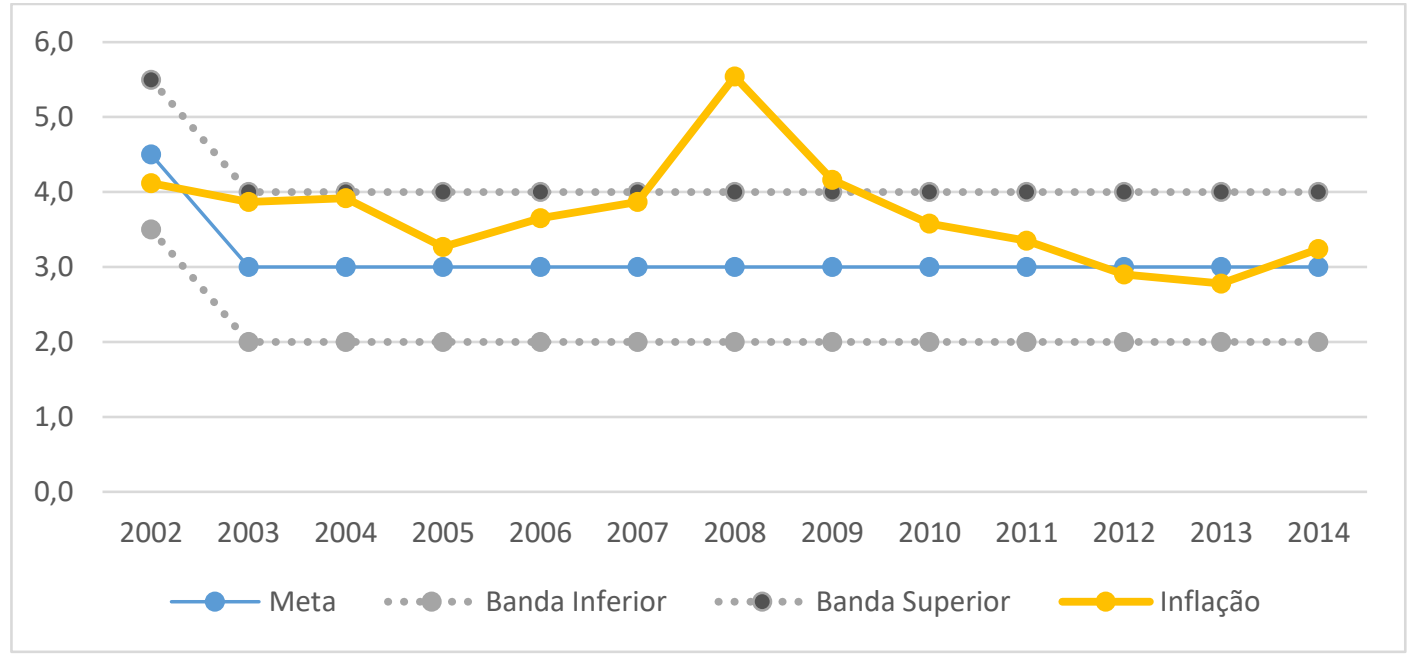

Fonte: Banco Central do México. Elaboração do autor. 
Conforme pode ser observado no gráfico 2, o Banco Central Mexicano tem obtido um enorme sucesso ao atingir as metas estabelecidas, somente no ano de 2008 a inflação ultrapassou a meta. Mesmo com bandas estreitas, apenas 1 p.p., a inflação tem atingido a meta e ficado em patamares estáveis no México.

No Brasil, com a implementação do Plano Real a economia brasileira iniciou um processo de estabilização de preços, no início a âncora cambial foi utilizada para controlar a inflação. Com a crise de confiança que se instalou em 1998, ocorreu uma fuga de capitais estrangeiros aplicados no Brasil e reservas do país diminuíram drasticamente. Dada esta situação, segundo Leal e Feijó (2011), o Brasil adotou o regime de metas de inflação em 1999, como estratégia de política monetária para direcionar as expetativas inflacionárias após abandonar o regime de câmbio fixo que era insustentável. Estabeleceu se que o Conselho Monetário Nacional é o responsável por fixar a meta de inflação e seu intervalo de tolerância, ao Banco Central coube a responsabilidade de executar as políticas necessárias para o cumprimento da meta estabelecida. Também é sua atribuição publicar trimestralmente um relatório da inflação, no qual aborda o desempenho das políticas implementadas, os resultados de suas decisões e as perspectivas para a inflação.

O Banco Central do Brasil foi criado em 31 de dezembro de 1964 pela Lei n 4595/64, a composição atual da diretoria são oito diretores e um presidente. O regime monetário vigente desde 1999 é o regime de metas de inflação, também naquele ano abandonou-se o regime de câmbio fixo e adotou-se o regime de câmbio flutuante, sendo desde 2006 a meta da inflação fixada em 4,5\% com banda em 2 p.p. (BCB, 2016). Sendo desde a adoção do regime de metas de inflação a política monetária brasileira caracterizada pela adoção do tripé econômico: superávit primário, câmbio flutuante e metas de inflação. Em 1996 criou-se o Comitê de Política Monetária com a função de determinar as diretrizes da política monetária brasileira, determinando a taxa básica de juros da economia. Este mesmo comitê é o responsável por publicar trimestralmente o Relatório de Inflação que similar ao do Banco Central do Chile, divulga informações e projeções sobre os principais assuntos econômicos.

Conforme Mishkin (2004), o regime de metas de inflação não apenas requer uma boa comunicação e transparência por parte do banco central, mas também políticas que visem sustentabilidade fiscais e das instituições financeiras. Os autores apontam que no Brasil estas políticas não foram totalmente empregadas durante o período com metas inflacionárias, no qual é necessário um forte compromisso para desenvolver estas ações e reforçar as questões fiscais, financeiras e monetárias para obter melhores resultados. Durante o período de 2002 a 
2014, a inflação brasileira não ficou entre as bandas estabelecidas somente nos anos de 2002 e 2003, como se pode analisar no gráfico abaixo.

Gráfico 3: Taxas de inflação registradas no Brasil

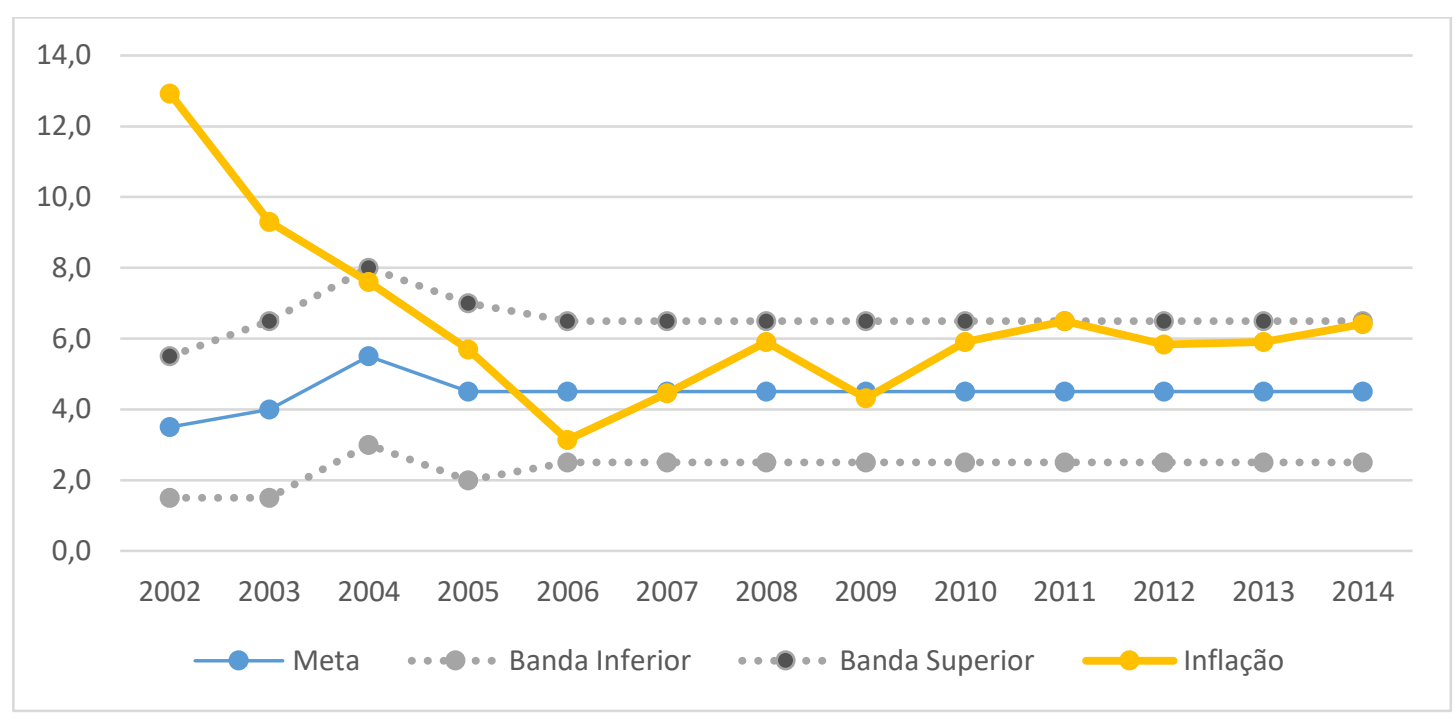

Fonte: Banco Central do Brasil. Elaboração do autor.

Na Colômbia, o regime de metas de inflação vinha tentando ser adotado desde 1991, como aborda Monteiro (2006), porém devido a problemas fiscais e cambiais conseguiu adotalo somente em 1999. O Banco Central da Colômbia foi criado em 1923, desde então sofreu diversas reformas com o objetivo de melhorar seu papel na condução da política monetária colombiana, com destaque para a alteração constitucional de 1991, onde se definiu que o seu principal objetivo é o de preservar o poder de compra da moeda nacional. A inflação baixa e estável, segundo BANREP (2016), é considerada importante para a sociedade pelos seguintes fatores: (i) baixas taxas de inflação promovem um eficiente uso dos recursos produtivos; (ii) uma taxa de inflação baixa reduz as incertezas; (iii) favorece os investimento, devido a estabilidade favorece a confiança nas decisões de investimentos; e (iv) evita uma distribuição arbitrária dos salários e da riqueza. 
Gráfico 4: Taxas de inflação registradas na Colômbia

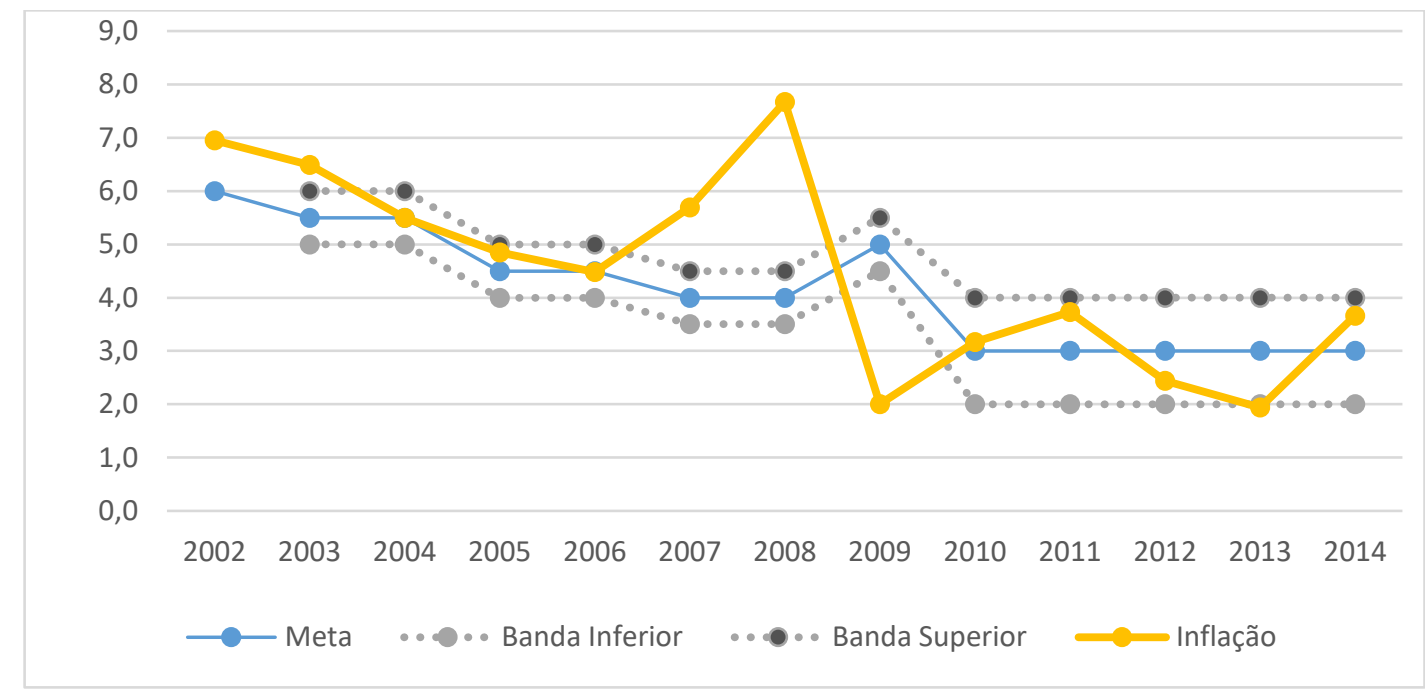

Fonte: Banco Central da Colômbia. Elaboração do autor.

O gráfico 4 apresenta os dados referentes a inflação colombiana, observa-se que dentre os países analisados no presente artigo a Colômbia é o país que mais alterou a meta de inflação no período estudado, foram cinco alterações. Contudo, pode se observar que a Colômbia obteve êxito ao conduzir o regime de metas de inflação, foram quatro anos que não conseguiu cumprir a meta, mas manteve a inflação em patamares baixos e estáveis.

O Banco Central de Reserva do Peru (doravante, denominado por BCRP) originou-se em março de 1922 com o objetivo de ser o órgão responsável em adequar a quantidade de dinheiro da economia com a demanda do mesmo, emitir o papel-moeda, financiar o governo e conceder empréstimos aos bancos privados em última instância (ORREGO, 2007). Com a promulgação da Constituição de 1993 o banco absorveu certa autonomia em suas decisões baseadas em critérios técnicos com a finalidade de garantir a estabilidade da moeda. Ao longo deste período o banco teve diferentes organogramas em seu conselho diretor, atualmente o 
mesmo é composto por um presidente, um vice-presidente e cinco diretores, sendo que os membros deste conselho somente podem ser afastados por infração grave (BCRP, 2016b).

A independência legal do BCRP que elevou-se a partir dos anos 90 com a nova constituição e com a Lei Orgânica do BCRP, possibilitaram uma melhor condução da política monetária em prol da estabilidade dos preços (REÁTEGUI, 2007). O Banco Central de Reserva do Peru adotou em 2002 o regime monetário de metas de inflação (BCRP, 2016b). Também no início dos anos 2000, de acordo com Dancourt (2015), o BCRP adotou a estratégia de acumular reservas internacionais para atender as suas necessidades, e não ser tão vulnerável ao ambiente externo desfavorável ou a ataques especulativos contra a sua moeda. Conforme Quispe e Rossini (2010) esta estrutura preventiva de acumular reservas deve-se a crise da Rússia em 1998, que resultou em uma desvalorização real da moeda peruana em 13\%. Desde de 2007, a meta de inflação estabelecida foi de 2 p.p. com uma tolerância de desviou em 1 p.p., o regime cambial adotado é o de câmbio flutuante.

Conforme defendido por Reátegui (2007) o BCRP tem avançado significativamente, no que se refere a transparência da execução da política monetária, principalmente desde 2002 quando publicou o primeiro relatório da inflação, que a partir de 2009, é publicado trimestralmente, o qual divulga informações e perspectivas sobre o cenário econômico internacional, balança de pagamentos, atividade econômica, finanças públicas, política monetária e projeções da taxa de inflação esperada.

Gráfico 5: Taxas de inflação registradas no Peru

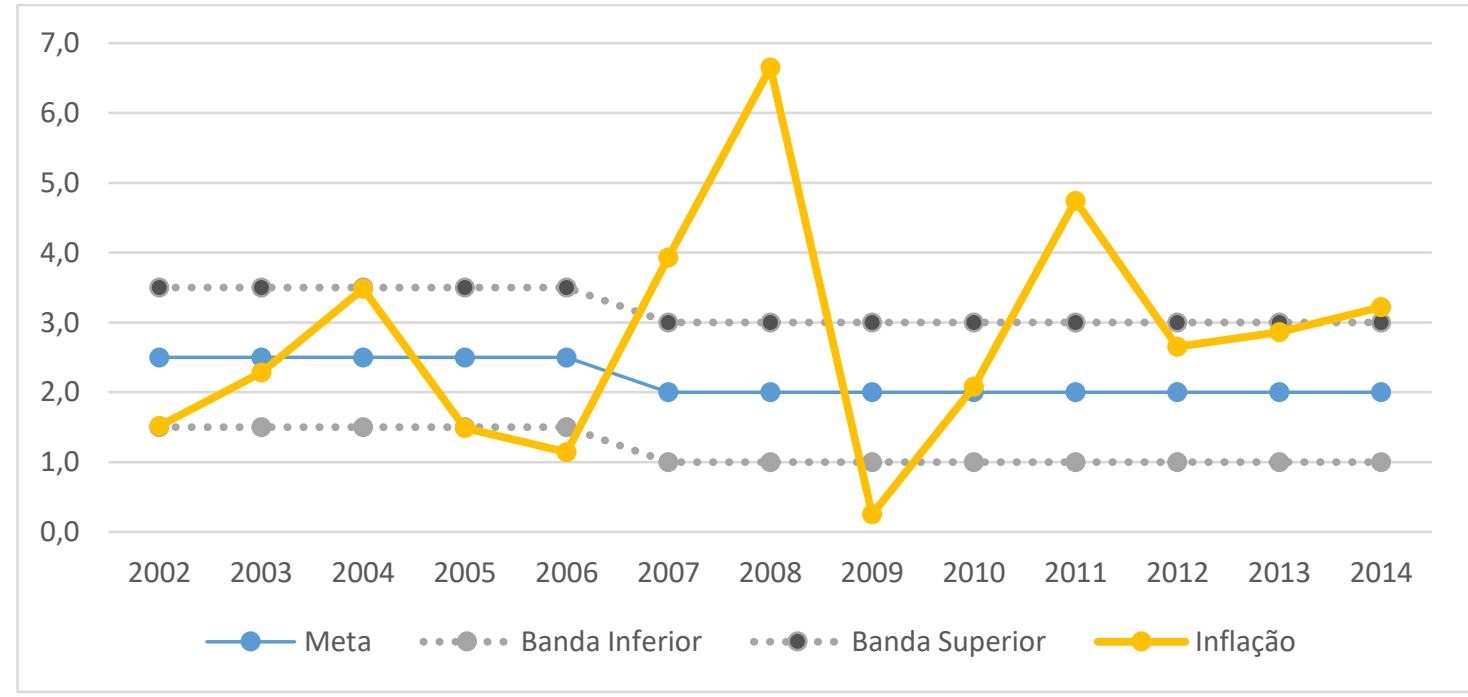

Fonte: Banco Central do Peru. Elaboração do autor. 
O gráfico 5 apresenta os dados referentes ao Peru sob o regime de metas de inflação, observa se que durante todo o período estudado a meta e suas bandas sofreram apenas uma única alteração durante o período entre 2006 e 2007. A meta peruana é a mais baixa dos países estudados, e próxima a inflação desejada pelos países desenvolvidos. Por estas razões, por mais que em seis anos o Peru não atingiu a meta proposta, é considerado um sucesso conforme estudo de Dancourt (2015).

Quadro 1: Sínteses dos indicadores dos regimes de metas dos países da América Latina selecionados no artigo

\begin{tabular}{|c|c|c|c|c|c|}
\hline Indicadores & Brasil & Chile & Colômbia & México & Peru \\
\hline Adoção & 1999 & $1990 / * 1999$ & 1999 & 2001 & 2002 \\
\hline $\begin{array}{c}\text { Institutional / } \\
\text { Fixação da meta }\end{array}$ & $\mathrm{CMN}$ e BC & $\begin{array}{c}\text { BC } \\
\text { independente }\end{array}$ & $\begin{array}{l}\text { Governo e BC } \\
\text { Independente }\end{array}$ & $\begin{array}{l}\text { Governo e BC } \\
\text { Independente }\end{array}$ & $\begin{array}{l}\text { Governo e BC } \\
\text { Independente }\end{array}$ \\
\hline Objetivo & $\begin{array}{c}\text { Estabilidade dos } \\
\text { preços e do } \\
\text { Sistema } \\
\text { financeiro } \\
\end{array}$ & $\begin{array}{c}\text { Inflação baixa e } \\
\text { estável }\end{array}$ & $\begin{array}{c}\text { Inflação baixa e } \\
\text { estável }\end{array}$ & $\begin{array}{c}\text { Estabilidade da } \\
\text { moeda e do } \\
\text { Sistema } \\
\text { financeiro } \\
\end{array}$ & $\begin{array}{c}\text { Inflação baixa e } \\
\text { estável }\end{array}$ \\
\hline $\begin{array}{l}\text { Índice } \\
\text { de referência } \\
\end{array}$ & IPCA & IPCA & $\begin{array}{c}\text { Núcleo do IPC } \\
* *\end{array}$ & IPC & IPC \\
\hline $\begin{array}{l}\text { Horizonte } \\
\text { temporal }\end{array}$ & Anual & Bianual & $\begin{array}{c}\text { Anual } \\
\text { (18 meses) }\end{array}$ & $\begin{array}{c}\text { Curto prazo - } 12 \\
\text { meses } \\
\text { Longo - } 4 \text { anos }\end{array}$ & $\begin{array}{l}\text { Em todo } \\
\text { momento }\end{array}$ \\
\hline $\begin{array}{c}\text { Instrumento da } \\
\text { Política } \\
\text { Monetária } \\
\end{array}$ & $\begin{array}{l}\text { Taxa de juros } \\
\text { Over/ Selic }\end{array}$ & $\begin{array}{c}\text { Taxa de juros } \\
\text { Overnight }\end{array}$ & $\begin{array}{c}\text { Taxa de juros } \\
\text { Overnight }\end{array}$ & $\begin{array}{l}\text { Regulação da } \\
\text { liquidez }\end{array}$ & $\begin{array}{c}\text { Taxa de juros } \\
\text { Overnight }\end{array}$ \\
\hline Meta atual (\%) & $4,5+/-2$ & $3,0+/-1$ & $3,0+/-1$ & $3,0+/-1$ & $2,0+/-1$ \\
\hline $\begin{array}{c}\text { Taxa de } \\
\text { Inflação na } \\
\text { adoção }(\%) \\
\end{array}$ & 3,3 & 3,2 & 9,0 & 9,0 & $-0,1$ \\
\hline $\begin{array}{c}\text { Taxa de juros } \\
* * *\end{array}$ & 14,15 & 3,50 & 7,25 & 3,75 & 4,25 \\
\hline
\end{tabular}

Fonte: Bancos centrais dos países e Hammond (2012)

* Informal e formal respectivamente. ** Exclusão dos preços dos alimentos e de alguns preços administrados. $* * * \%$ ao ano em jun/2016

Nota: CMN significa Conselho Monetário Nacional e BC Banco Central.

\section{REVISÃO DOS ESTUDOS EMPÍRICOS}

Conforme relatório do FMI (2014) o regime de metas de inflação não é muito popular em países desenvolvidos, são apenas oito países ${ }^{5}$ que adotam esse regime monetário. Isso pode ser compreendido pelo fato de dois dos principais bancos centrais do mundo (FED 6 e

\footnotetext{
${ }^{5}$ Austrália, Canadá, Islândia, Nova Zelândia, Noruega, Japão, Suécia e Reino Unido.

${ }^{6}$ Federal Reserve Bank, que é o Banco Central dos Estados Unidos.
} 
$\mathrm{BCE}^{7}$ ) não adotarem o regime de metas de inflação, ao menos não de forma explícita. Broto (2008) analisou oito países da América Latina, cinco que adotaram o regime de metas de inflação e três que não adotaram este regime monetário, o seu trabalho teve como propósito avaliar os possíveis benefícios resultantes de tal regime como baixa inflação e volatilidade. $\mathrm{O}$ modelo Q-STARCH foi utilizado para os testes empíricos. A autora concluiu que, em geral, o regime de metas de inflação tem sido eficiente para reduzir a inflação e sua volatilidade. Os resultados encontrados, exceto na Colômbia, apontam que há presença de heterocedasticidade, o que implica que os benefícios gerados pelo regime de metas de inflação afetam a inflação futura.

Os países emergentes possuem maior dificuldade em implementar e conduzir um regime de meta de inflação do que os países desenvolvidos. Para Fraga et al (2003), essa dificuldade se deve ao fato, via de regra, da autoridade monetária ter pouco credibilidade perante o público, um ambiente econômico instável e instituições fracas. Como resultado, a expectativa por parte do público que em determinado momento a autoridade monetária tende a se desviar da regra, acaba aumentado às expectativas de inflação acima dos países desenvolvidos. Tal tato também é apontado por Zettel (2006). Assim, quando ocorrem choques adversos na economia que exigem por parte das autoridades monetárias ações rigorosas para manter a credibilidade, o que tende a afetar negativamente o crescimento do produto.

É usual em países emergentes que o presidente do Banco Central, e não a instituição com suas regras, o responsável por transmitir credibilidade ao mercado. Logo caso ocorra uma elevada rotatividade do cargo, o resultado é uma elevação nos custos para construir desta credibilidade, conforme argumenta Zettel (2006). Dias et al. (2013) realizaram uma estimativa do efeito da rotatividade dos diretores do Banco Central do Brasil sobre a determinação da taxa de juros, entre 2001 a 2008, utilizada como forma de atingir as metas de inflação no Brasil. A metodologia adotada foi um modelo de vetores auto-regressivos estruturais (SVAR). Os resultados encontrados indicam que a rotatividade do cargo no longo prazo é uma variável significativa que tende a resultar em um aumento de expectativas da taxa de inflação, por parte dos agentes, implicando taxas de juros mais altas, que causam um custo social na economia maior.

A ligação coordenada entre as políticas fiscais e monetárias é recomenda independentemente de qual regime monetário que o país utiliza, um exemplo desta

\footnotetext{
${ }^{7}$ Banco Central Europeu.
} 
importância conforme Zettel (2006), é que na existência de uma dívida pública elevada as expectativas inflacionárias, em geral, se elevam. Para então conter estas expectativas inflacionárias o Banco Central adota política de elevação na taxa de juros, o que, por sua vez aumentará a dívida pública resultando novamente em expectativas inflacionárias. A falta de disciplina fiscal e a restrição externa, comumente apresentada em países em desenvolvimento, são elementos que dificultam o atingimento da meta de inflação.

Quadro 2: Resumo de estudos que analisaram o regime de metas de inflação

\begin{tabular}{|c|c|c|c|c|}
\hline Estudo & Período & Método & Objetivo & Resultados \\
\hline $\begin{array}{l}\text { Souza e } \\
\text { Alves } \\
(2010)\end{array}$ & 1999-2009 & $\begin{array}{l}\text { Mecanismo de } \\
\text { Correção de } \\
\text { Erros (VEC), } \\
\text { VAR e SVAR }\end{array}$ & $\begin{array}{l}\text { Analisar teórica e } \\
\text { empiricamente a relação } \\
\text { entra e taxa de câmbio e } \\
\text { preços no Brasil. }\end{array}$ & $\begin{array}{l}\text { O pass-through muito elevado devem-se ao fato da mudança } \\
\text { do regime cambial de fixo para flexível, o apagão de energia } \\
\text { elétrica em } 2001 \text {, o processo eleitoral em } 2002 \text { e a fatores } \\
\text { externos como o atentado ao World Trade Center e a crise. } \\
\text { No período mais estável da economia brasileira, com } \\
\text { crescimento produto do emprego, estabilidade de preços e } \\
\text { uma tendência de apreciação cambial, o grau de passagem } \\
\text { cambial foi um pouco menor. }\end{array}$ \\
\hline $\begin{array}{c}\text { Couto e } \\
\text { Fraga }(2014)\end{array}$ & $1999-2000$ & $\begin{array}{l}\text { Mecanismo de } \\
\text { Correção de } \\
\text { Erros (VEC) }\end{array}$ & $\begin{array}{c}\text { Analisar a relação entre a } \\
\text { taxa de câmbio e preços no } \\
\text { Brasil, no longo prazo. }\end{array}$ & $\begin{array}{l}\text { A relação entre o pass-through da taxa câmbio e os índices } \\
\text { de preços no longo prazo é estatisticamente significante ou o } \\
\text { repasse é quase completo. }\end{array}$ \\
\hline $\begin{array}{l}\text { Josifidis et } \\
\text { al. (2009) }\end{array}$ & $1990-2009$ & $\begin{array}{c}\text { Modelo } \\
\text { VAR/VEC }\end{array}$ & \begin{tabular}{|c|} 
Investigar a alteração da \\
ancora nominal e do regime \\
câmbio para a Polônia, \\
República Checa, \\
Eslováquia e Servia. \\
\end{tabular} & $\begin{array}{l}\text { A estratégia monetária da Polônia têm sido gradual, } \\
\text { planejada e com alterações suaves. O pass-through da taxa } \\
\text { câmbio é significante estatisticamente. }\end{array}$ \\
\hline $\begin{array}{l}\text { Triches e } \\
\text { Santaroosa } \\
\quad(2013)\end{array}$ & $1995-2010$ & $\begin{array}{l}\text { Mecanismo de } \\
\text { Correção de } \\
\text { Erros (VEC) }\end{array}$ & \begin{tabular}{|c|} 
Investigar os efeitos e os \\
canais de transmissão de \\
política monetária nos \\
países selecionados da \\
América Latina
\end{tabular} & $\begin{array}{c}\text { A política monetária seguida pelos bancos centrais com } \\
\text { regime de meta de inflação como Brasil, Chile, México e } \\
\text { Peru apresentou, em geral, efeitos de transmissão sobre as } \\
\text { variáveis macroeconômicas. }\end{array}$ \\
\hline $\begin{array}{c}\text { Nogueira et } \\
\text { al. (2013) }\end{array}$ & 1999-2011 & \begin{tabular}{|c|} 
Vetores \\
autorregressivos \\
estruturais \\
(SVAR) com \\
vetores de \\
correção de \\
erros (VEC). \\
\end{tabular} & \begin{tabular}{|} 
Estimar o repasse cambial \\
em diferentes níveis e \\
agregações de preços
\end{tabular} & $\begin{array}{c}\text { Os resultados mostram que houve significativa redução do } \\
\text { nível pass-through nos últimos anos. Esse fato corroboram a } \\
\text { teoria de que o pass-through depende diretamente da } \\
\text { credibilidade da política econômica e de um ambiente de } \\
\text { maior estabilidade macroeconômica. }\end{array}$ \\
\hline Broto (2008) & $1995-2008$ & $\begin{array}{c}\text { Modelo Q- } \\
\text { STARCH }\end{array}$ & $\begin{array}{l}\text { Analisar a dinâmica da } \\
\text { inflação em oito países da } \\
\text { América Latina. }\end{array}$ & $\begin{array}{c}\text { Os resultados empíricos sugerem que a adoção do regime de } \\
\text { metas de inflação tem reduzido no nível de inflação e sua } \\
\text { volatilidade. }\end{array}$ \\
\hline
\end{tabular}

Fonte: Elaboração do autor.

Biondi e Toneto (2008) analisaram os impactos da adoção do regime de metas de inflação sobre a inflação e o crescimento real do produto interno bruto para países desenvolvidos e em desenvolvimento por meio da metodologia de dados em painel, coletaram informações estatísticas das variáveis inflação, ao crescimento real do PIB, dívida total do 
setor público, superávit primário do governo, saldo da balança comercial, reservas em moeda estrangeira, taxa nominal de câmbio e taxa real de juros. Os autores concluíram que os países que adotaram o regime de metas de inflação experimentaram reduções relevantes em suas médias de inflação quando comparado a países que não adotaram este regime. Constataram ainda que há um custo em relação ao crescimento real do PIB, porque os países que adotaram o regime de metas de inflação tendem a apresentaram uma taxa de crescimento menor em relação aos países em desenvolvimento que não o adotaram.

Wu (2004) analisou dados trimestrais entre 1985 a 2002 de 22 países industriais membros da OECD, com o objetivo de verificar os reais efeitos da adoção do regime de metas de inflação no desempenho econômico dos países. Os resultados evidenciam que os países que adotaram oficialmente o regime de metas de inflação obtiveram um declínio, em geral, em suas taxas médias de inflação. Também os resultados apontam que não há evidências que nos países que adotaram o regime de metas de inflação houve uma elevação significativa na taxa real de juros.

Pinto e Vilela (2007) analisaram as experiências latino-americanas com câmbio flexível e metas de inflação com o objetivo de se entender a dinâmica da taxa de câmbio e da inflação em um modelo monetário. Em economias abertas a taxa de câmbio é um mecanismo de transmissão da política monetária impactando diretamente a formação de preços na economia, desta forma os autores buscaram compreender o comportamento do câmbio e da inflação quando se adota o regime de câmbio flexível e metas de inflação. Adotou-se a metodologia VAR na realização dos testes empíricos, para se analisar os resultados a análise de decomposição de variância e as funções de impulso-resposta foram aplicadas. Os resultados encontrados pelos autores indicam que para Brasil e Chile a taxa de câmbio é um fator significativo na explicação da variância da taxa de inflação, sugerindo a existência de um grau de repasse do câmbio aos preços.

Andersen, Moller e Nordvig (2014) investigaram se os países que adotavam o regime de metas de inflação durante o período das crises financeiras internacionais entre 2007 a 2012, se beneficiaram em termos de crescimento econômico. Os autores afirmam que sim, em seus resultados encontrados através de dados em painel, indicam que estes países se beneficiaram em termos de crescimento econômico, principalmente frente aos países que adotavam o regime de câmbio fixo. Em parte este crescimento deve-se a uma melhor performance nas exportações durante os anos iniciais da crise, o que pode ser explicado por uma depreciação real na taxa de câmbio, estratégia monetária que não é possível em regime de câmbio fixo. Os 
resultados indicam que a escolha do regime monetária adotado pode influenciar o crescimento econômico de um país, especialmente em períodos onde a flexibilização é um fator chave.

\section{CONSIDERAÇÕES FINAIS}

Com o presente artigo buscou-se enriquecer o debate acerca do regime de metas de inflação com o objetivo de demonstrar as concepções teóricas desse regime monetário e sua condução em cinco países da América Latina que o utilizam. Desta forma, ao longo do artigo se buscou apresentar e discutir os principais pontos acerca desta política monetária que possui pouco mais de 25 anos desde a sua primeira implantação.

O regime de metas de inflação é considerado por diversos economistas como a melhor alternativa de regime monetário com âncora nominal. Esse tem a capacidade de responder aos choques econômicos domésticos, fato que não é possível por exemplo num regime de câmbio fixo. Nos países analisados, conforme ilustrado pelos gráficos no decorrer do artigo, o regime de metas de inflação obteve sucesso ao atingir patamares relativamente baixos e estáveis da inflação. Por mais que a inflação se comportou, em alguns períodos, de maneira distinta nos países estudados, isto era previsto pela particularidades presentes em cada economia, conforme abordado no estudo de Neves e Oreiro (2008). Por fim, esta estrutura de política monetária, de modo geral, tem obtido um resultado no mínimo satisfatório no controle da inflação nos países estudados.

\section{REFERÊNCIAS}

ABO-ZAID, Salem; TUZEMEN, Didem. Inflation targeting: A three decade perspective. Journal of Policy Modeling, p. 621-645, dez. 2012.

ANDERSEN, Thomas Barnebeck, MOLLER, Nikolaj Malchow e NORDVIG, Jens. Inflation targeting, flexible exchange rates, and macroeconomic performance since the Great

Recession. Centre for European Policy Studies, Working Document, n. 394, mar. 2014.

ARETIS, Philip. Inflation targeting: a critical appraisal. The Levy Economics Institute of Bard College, n. 388, Set, 2003. NY EUA. Disponível em <http://www.levyinstitute.org/pubs/wp388.pdf> Acessado em 03 abr. 2016.

AYRES, Kelly.; BELASEN, Ariel; KUTAN, Ali M. Does inflation targeting lower inflation and spur growth? Journal of Policy Modelling, n. 36, p. 373-388, 2014.

BALL, Laurence. The Performance of Alternative Monetary Regimes, in K. J. Arrow and M. D. Intriligator (eds.), Handbook of Monetary Economics, p. 1303-1343, 2011. 
BALL, Laurence; SHERIDAN, Niamh. Does Inflation Targeting Matter.The Inflation Targeting Debate, NBER Studies in Business Cycles, Vol. 32, University of Chicago Press, Chicago, 2005.

BANCO CENTRAL DE COLOMBIA. Politica monetaria: La estrategia de inflacion objetivo en Colombia. Disponível em: 〈http://www.banrep.gov.co/es/politica-monetaria〉. Acessado em 15 jun. 2016.

BANCO CENTRAL DO BRASIL (BCB). Histórico das Metas para inflação. Disponível em: 〈http://www.bcb.gov.br/pec/metas/tabelametaseresultados.pdf >. Acessado em: 22 abr. 2016.

BANCO CENTRAL DO CHILE (BCC). Política Monetaria. Disponível em:

$<$ http://www.bcentral.cl/es/faces/pmonetaria?_afrLoop=691305998230376\&_afrWindowMod e=0\&_afrWindowId=1bttc56i27_1\#!\%40\%40\%3F_afrWindowId\%3D1bttc56i27_1\%26_afrL oop\%3D691305998230376\%26_afrWindowMode\%3D0\%26_adf.ctrltate\%3D1bttc56i27_185>. Acesso em: 03 maio 2016.

BANCO CENTRAL DO PERU (BCRP). Monetary Policy. Disponível em: <http://www.bcrp.gob.pe/monetary-policy.html> Acessado em: 22 jun. 2016.

BANCO DO MÉXICO (BM). Política monetaria e inflación. Disponível em: <http://www.banxico.org.mx/politica-monetaria-e-inflacion/index.html>. Acessado em: 18 abr. 2016.

BARBOSA, Fernando de Holanda. A inércia da taxa de juros na política monetária. Ensaios Econômicos, Fundação Getúlio Vargas, n. 534, mar. 2004.

BATINI, Nicoletta; KUTTNER, Kenneth; LAXTON, Doug. Does Inflation Targeting Work in Emerging Markets? IMF World Economic Outlook, set. 2005.

BIONDI, Roberta L. O regime de metas inflacionarias e sua adequação ao caso brasileiro: Os custos de manutenção do regime. 2006. Dissertação (Mestrado em Economia) - Universidade de São Paulo, Ribeirão Preto, 2006.

BIONDI, Roberta L.; TONETO, Rudinei. Regime de metas inflacionárias: os impactos sobre o desempenho econômico dos países. Revista Estudos Econômicos, São Paulo, v. 38, n. 4, p. 873-903, out/dez. 2008.

BONGA-BONGA, Lumengo; KABUNDI, Alain. Monetary Policy Instrument and Inflation in South Africa: Structural Vector Error Correction Model Approach. University of Johannesburg, abr. 2015.

BRITO, Ricardo; BYSTEDT, Brianne. Inflation Targeting in Emerging Economies: Panel Evidence, Journal of Development Economics, n. 91, p. 198-210, 2010.

BRITO, Ricardo; BYSTEDT, Brianne. The macroeconomic effects of inflation targeting in Latin America. Ibmec Sao Paulo Working Papers, 2006. 
BROTO, Carmen. Inflation Targeting in Latin America: Empirical Analysis using GARCH Models. Documentos de Trabajo, n. 826, Banco de Espana, 2008.

CABRAL, Konras Pereira da Costa Figueiredo. Os Impactos do regime de metas para a inflação sobre o nível e a volatilidade do produto: uma resenha da literatura. Dissertação (Mestrado em Economia) - Universidade Federal do Rio de Janeiro, Rio de Janeiro, 2013.

CARVALHO, Fernando J. Cardim de.; SOUZA, Francisco Eduardo Pires de.; SICSÚ, João; PAULA, Luiz Fernando Rodrigues de.; STUDART, Rogério. Economia Monetária e Financeira. Rio de Janeiro: Elsevier, 2007.

CECCHETTI, Stephen G.; EHRMANN, Michael. Does Inflation Targeting Increase Output Volatility? An International Comparison of Policymakers' Preferences and Outcomes.

National Bureau of Economic Research, working paper n. 7426, dez. 1999.

COUTO, Sílvia Verônica Vilarinho; FRAGA, Gilberto Joaquim. O pass-though da taxa de câmbio para índices de preços: análise empírica para o Brasil. Revista de Economia Contemporânea, v. 18, n. 3, p. 333-356, set/dez. 2014.

CORBO, Vittorio; HERNANDEZ, Leonardo. Ochenta Anos de Historia del Banco Central de Chile. Documentos de Trabajo, Banco Central de Chile, n. 345, 2005.

DANCOURT, Oscar. Inflation Targeting in Peru: The reasons for the success. Comparative Economic Studies, v. 57, n. 3, p. 511-538, 2015.

DIAS, Maria Helena Ambrosio; DIAS, Joilson; TEIXEIRA, Anderson Mutter. New macroeconomic consensus and inflation targeting: Monetary Policy Committee directors' turnover in Brazil. ENCONTRO NACIONAL DE ECONOMIA, XLI, 2013, Foz do Iguaçu. Anais, v. 14, p. 158-170, set/dez, Niterói (RJ): ANPEC, 2013.

FRAGA, Armínio; GOLDFAJN, Ilan; MINELLA, André. Inflation targeting in emerging market economies. Trabalhos para discussão, n. 76, Banco Central do Brasil, jun. 2003.

GALINDO, Luis Miguel; ROS, Jaime. Banco de México: política monetaria de metas de inflación. Economíaunam. vol 3, n.9, 2006.

HAMMOND, Gill. State of the art of inflation targeting. Centre for Central Banking Studies, Bank of England, n. 29, 47 p., fev. 2012.

HEBBEL-SCHMIDT, Klaus. Inflation targeting twenty years on: where, when, why, with what effects, what lies ahead? Instituto de Economia, Working Paper n. 360, Catholic University of Chile, out. 2009.

IMF (International Monetary Fund). Annual Report on Exchange Arrangements and Exchange Restrictions. Publication Services, 109p. Washington, out. 2014.

IMF (International Monetary Fund). World Economic Outlook. Does Inflation targeting work in emerging market? Capítulo IV, Washington, 2005. 
JOSIFIDIS, Kosta; ALLEGRET, Jean-Pierre; PUCAR, Emilija Beker. Monetary and exchange rate regimes changes: The cases of Poland, Czech Republic, Slovakia and Republic of Serbia. Panoeconomicus, v. 58, n. 2, p. 199-226, 2009.

LEAL, Ricardo Aguirre; FEIJÓ, Flavio Tosi. O regime de metas de inflação foi a melhor escolha para o Brasil? Economia \& tecnologia, Curitiba, v. 24, p.43-52, jan/mar. 2011.

KING, Mervyn. Monetary Policy: Practice Ahead of Theory. Mais Lecture 2005, Cass Business School, City University, London, mai. 2005.

MENDONÇA, Helder Ferreira de., Metas de inflação: uma análise preliminar para o caso brasileiro. Economia Aplicada. v. 5, n.1, p.129-158, 2001.

MISHKIN, Frederic S. Inflation targeting in emerging market countries. National Bureau of Economic Research, working paper n. 7618 mar. 2000.

International experience with monetary policy regimes. National Bureau of Economic Research, 48 p., working paper n. 6965, fev. 1999.

Can inflation target work in emerging market countries? National Bureau of Economic Research, working paper n. 10646, jul. 2004.

MOLLICK, André V.; TORRES, René C.; CARNEIRO, Francisco. Does inflation targeting matter for output growth? Evidence from industrial and emerging economies. Policy

Research Working Papers, the world bank, n, 4791, dez. 2008.

MONTEIRO, João Evangelista Dias. Regimes de Metas de Inflação: Teoria e Prática. Tese (Doutorado em Economia) - Universidade Federal do Rio de Janeiro, Rio de Janeiro, 2006.

MORANDÉ, Felipe G. A decade of inflation targeting in Chile: Developments, lessons, and challenges. Central Bank of Chile. Santiago, Chile, 2002.

NEVES, André Lúcio; OREIRO, José Luís. O regime de metas de inflação: uma abordagem teórica. Ensaios FEE, Porto Alegre, v. 29, n. 1, p. 101-132, jun. 2008.

NOGUEIRA, Veridiana de Andrade; MORI, Rogério; MARÇAL, Emerson Fernandes. Transmissão da variação cambial para as taxas de inflação no Brasil: estimação do passthrough através de modelos de vetores autorregressivos estruturais com correção de erros. CEMAP, Fundação Getúlio Vargas, n. 4, dez, 2013.

NUNES, Maria Andréia dos Santos. Inflação e política monetária - Uma avaliação da experiência brasileira com o regime de metas de inflação (1999-2012). 2014. Dissertação (Mestrado em Economia) - Universidade Federal do Rio Grande do Sul, Porto Alegre, 2014.

ORREGO, Fabrizio. Autonomía del Banco Central de Reserva del Perú: Una perspectiva histórica. Revista Moneda, n. 135, p. 16-22, maio 2007. Disponível em:

$<$ http://www.bcrp.gob.pe/docs/Publicaciones/Revista-Moneda/Moneda-135/Revista-Moneda135-04.pdf>. Acesso em: 03 maio 2016. 
POOTER, Michiel de; ROBITAILLE, Patrice; WALKER, Ian; ZDINAK, Michael. Are Long-Term inflations expectations well anchored in Brazil, Chile and Mexico? Internacional Finance Discussion Papers, Federal Reserve Board of Governors, n 1098, mar. 2014.

QUISPE, Zenon; ROSSINI, Renzo. Monetary policy during the global financial crisis of 2007-09: the case of Peru. Bank for internacional settlements papers, n. 54, Suíça, dez. 2010. Disponível em: <http://papers.ssrn.com/sol3/papers.cfm?abstract_id=1959828\#page=305>.

Acessado em 22 mai. 2016.

REÁTEGUI, Vicente Tuesta. Indepencia legal y efectiva del Banco Central de Reserva del Peru. Working Paper Series, n. 2007-012, ago. 2007. Disponível em:

<http://www.bcrp.gob.pe/docs/Publicaciones/Documentos-de-Trabajo/2007/Working-Paper12-2007.pdf>. Acessado em 22 mai. 2016.

RODRIGUES, Orlando José Ferreira. Metas de inflação e modelagem de política monetária: compreendendo a experiência brasileira após 1999. Concurso de monografias. Bacen. 2003.

SILVA, Kellen Fraga da. Metas de inflação em economias emergentes: Uma avaliação empírica dos seus efeitos sobre o desempenho macroeconômico. 2007. Dissertação (Mestrado em Economia) - Universidade Federal do Rio Grande do Sul, Porto Alegre, 2007.

SILVA, Marcelo Eduardo Alves da. Metas de inflação: Uma análise da experiência brasileira. 2001. Dissertação (Mestrado em Economia) - Universidade Federal do Rio Grande do Sul, Porto Alegre, 2001.

SOUZA, Rodrigo Gustavo; ALVES, Alexandre Florindo. Relação entre Câmbio e Preços no Brasil: Aspectos Teóricos e Evidências Empíricas. ENCONTRO NACIONAL DE ECONOMIA, XXXVIII, 2010, Salvador. Anais, dez. Niterói (RJ): ANPEC, 2010.

TRICHES, Divanildo; SANTAROSSA, Eduardo Trapp. Os efeitos dos mecanismos de transmissão da política monetária: uma análise dos países selecionados da América Latina. Texto para discussão, n. 49, Universidade de Caxias do Sul, abr. 2013.

ZETTEL, Ana Paula França Vieira. A experiência de Chile, México e Brasil sob o regime de metas de inflação: uma comparação internacional. 2006. Dissertação (Mestrado em Economia) - Universidade Federal do Rio Grande do Sul, Porto Alegre, 2006.

WU, Thomas Y. Does Inflation Targeting Reduce Inflation? An analysis for the OECD Industrial Countries. Banco Central do Brasil, working paper series, n. 83, mai. 2004.

PINTO, Ana Carla Baduy; VILELA, Flávio Vilela Vieira. Câmbio flexível e metas de inflação em países selecionados da América Latina: Volatilidade e Análise VAR. Anais do XXXV Encontro de Economia da ANPEC, dez. 2007. 